\title{
The European Institute of Oncology in Milan
}

\author{
Umberto Veronesi \\ European Institute of Oncology, Milan, Italy
}

\section{The European Institute of Oncology}

The European Institute of Oncology (EIO) was established to implement an innovative model for health and advanced research in the international oncology field. In keeping with the standards of the most advanced international oncology centres, the institute fully integrates different activities involved in the fight against cancer: prevention and diagnosis, health education and training, research and treatment.

\section{Division of Senology}

Since the foundation of the European Institute of Oncology, clinical research in the Senology Division has been concerned with the development of new surgical techniques that improve not only the effectiveness of treatments for breast cancer, but also conserve as far as possible the integrity of the woman's body.

The Division has 32 beds, two operating theatres working every day (Saturday included), and one operating theatre for outpatients. Physiotherapy is offered to the patients during the immediate post-operative period. Psychological or psychotherapeutic consultations are available in the division on patient request or on referral by the clinician in charge. Outpatient clinics are held 5 days a week by the physicians of the division, aiming at early diagnosis of breast malignancies. In collaboration with the breast imaging unit, basic diagnostic workup of all patients with palpable and non-palpable breast lesions are performed. Devices for stereotactic biopsies (Mammotome ${ }^{\circledR}$ ) are available for patients with non-palpable breast lesions. Follow-up clinics are also offered to all patients Multidisciplinary case discussions are performed weekly.

The Division of Breast Surgery at the European Institute of Oncology started activity in 1994 . From the beginning, the
Table 1. IEO - Senology Activity

\begin{tabular}{lrr}
\hline & 2004 & 2005 \\
\hline Hospital admissions, n & 3,324 & 3,360 \\
Inpatients admissions, n & 2,995 & 2,925 \\
Day hospital, n & 7 & 5 \\
Day surgery, n & 322 & 430 \\
Average length of stay, days & 2.96 & 3.00 \\
Surgical admissions, n & 3,240 & 3,277 \\
Medical admissions, n & 84 & 83 \\
Surgery, n & 3,267 & 3,295 \\
Conservative surgery, n & 2,360 & 2,242 \\
\hline
\end{tabular}

Table 2. Origin of patients 2005

\begin{tabular}{lrrr}
\hline Place of origin, $n$ & Admission & Day hospital & Total \\
\hline Milan & 404 & 68 & 472 \\
Lombardy (Milan excepted) & 873 & 149 & 1,022 \\
Italy & 1,619 & 218 & 1,837 \\
Foreigner & 29 & 0 & 29 \\
Total & 2,925 & 435 & 3,360 \\
\hline
\end{tabular}

main goal was to integrate clinical research and surgical treatment of breast cancer. Due to close co-operation with other divisions of the Institute - at the laboratory and clinical level - improvements regarding treatment definition and planning, as well as progression of research in breast cancer therapy has been achieved. Breast conservation is the main aim of therapeutic strategies and depending on a high rate of early detection in the overwhelming majority of patients the breast can be preserved. Sentinel node biopsy, which has been developed in the institute in 1998, is now offered to patients as

\begin{tabular}{ll}
\hline KARGER & ( 2006 S. Karger GmbH, Freiburg \\
Fax +49 761 4520714 & Accessible online at: \\
$\begin{array}{l}\text { E-mail Information@Karger.de } \\
\text { www.karger.com }\end{array}$ & www.karger.com/brc
\end{tabular}


standard procedure. In co-operation with the division of plastic surgery patients undergoing breast conservation are also offered ipsilateral or bilateral breast remodelling and for patients undergoing mastectomy various techniques of immediate/ second step breast reconstruction are performed. The Division of Breast Surgery at the EIO operates on invasive breast cancers and DCIS; sentinel node biopsies are performed as well (table 1,2).

Radio-guided occult lesion localisation (ROLL) also developed in the institute to precisely localise sub-clinical lesions prior to excision biopsy is a standard procedure. The Division of Breast Surgery is actively participating, together with the
Breast Imaging Unit, in a mammography screening program for women between 50 and 69 years of age, in the Milan area. The Division is one of the reference centres for the surgical treatment of breast carcinomas detected by screening. Intraoperative radiotherapy with electrons (IORT-ELIOT) represents one of the main fields of clinical research and treatment. In cooperation with the department of radiotherapy, the medical physics unit, and the division of plastic surgery different applications of ELIOT in breast cancer, both in conservative and non-conservative surgery are under investigation. Two multi-energy IORT-ELIOT devices are available in the operating theatres. 